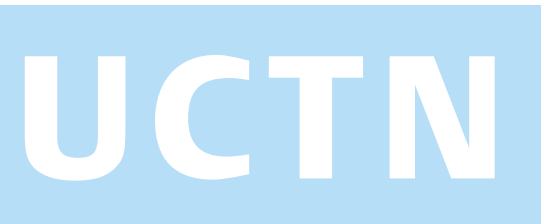

A 14-year-old Italian girl was admitted to our department because of acute pancreatitis. Her previous medical history included an episode of pancreatitis six months earlier. A physical examination gave negative findings. Biochemical investigation showed increased levels of serum amylase (660 IU/l, normal <220) and lipase (10000 IU/1, normal <300); abdominal ultrasound revealed only an enlarged pancreas. Pancreatitis due to increased levels of calcium and lipids, the use of alcohol or drugs, or cystic fibrosis was excluded. An endoscopic retrograde cholangiopancreatography (ERCP) was performed in a search for anatomical abnormalities of the pancreatic duct and biliary tree; unexpectedly, no proper papilla of Vater was detected but, near its usual location, there was a small hole through which bile was gushing (Figure 1). Contrast medium injected through the "hole" showed a normal small-bowel loop; this was confirmed by advancing a forward-viewing endoscope. Interestingly, the caudal part of the duodenum formed a smooth-surfaced polypoid mass covered by normal mucosa during air aspiration (Figure 2), which disappeared during air insufflation (Figure 1). A voluminous intraluminal duodenal diverticulum was finally diagnosed by means of

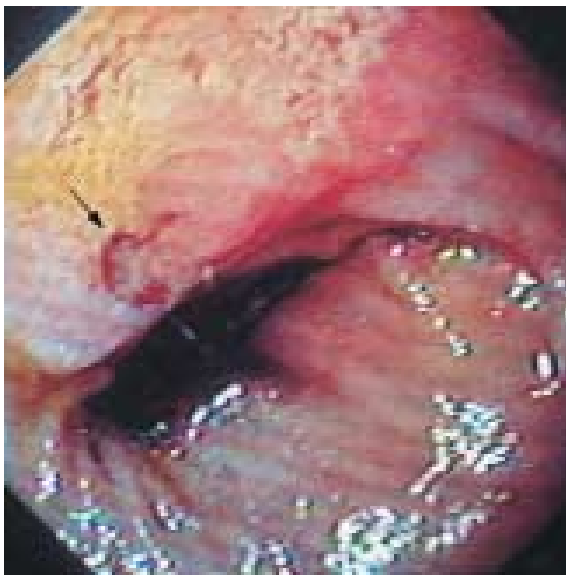

Figure 1 The second part of the duodenum during air insufflation, showing a small hole through which bile is gushing (arrow), and a lumen below, which was later diagnosed as an intraluminal duodenal diverticulum

\title{
An Unusual Endoscopic Feature in the Duodenum of a Young Girl With Intraluminal Duodenal Diverticulum
}

standard barium meal radiography, and surgically resected. The patient has so far been followed up every 3 months for 15 months and has not experienced any more bouts of pancreatitis; her serum amylase and lipase levels remain normal.

A diagnosis of intraluminal duodenal diverticulum should be considered by physicians looking for rare causes of pancreatitis, and the unusual endoscopic sign of a polypoid mass disappearing on insufflation should be interpreted as a warning of its presence. This type of diverticulum is due to abnormal duodenal development and has so far been reported in about 100 patients, mainly adult, $20 \%$ of whom had pancreatitis. The movements of the diverticulum presumably obstruct the papilla and induce pancreatitis [1-5].

\section{S. Massironi ${ }^{1}$, R. Penagini ${ }^{1}$,}

M. T. Bardella, V. Di Carlo ${ }^{2}$,

D. Conte ${ }^{1}$, M. Quatrini ${ }^{1}$

${ }^{1}$ Cattedra di Gastroenterologia,

Dipartimento di Scienze Mediche,

IRCCS Ospedale Maggiore, Milan, Italy

${ }^{2}$ Cattedra di Chirurgia Generale,

Divisione Chirurgia II, Ospedale

S. Raffaele, Milan, Italy

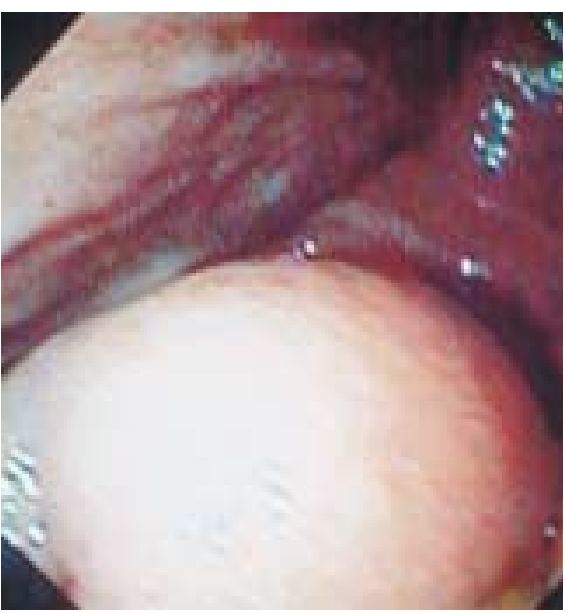

Figure 2 The second part of the duodenum during air aspiration, showing the emergence of a polypoid mass with a smooth surface covered by normal mucosa in the location of the lumen shown in Figure $\mathbf{1}$

\section{References}

${ }^{1}$ Boyd R. Description of a malformation of the duodenum. Lancet 1845; 1: 548

${ }^{2}$ Fleming CR, Newcomer AD, Stephens $\mathrm{DH}$ et al. Intraluminal duodenal diverticulum. Report of two cases and review of the literature. Mayo Clin Proc 1975; 50 (5): $244-248$

${ }^{3}$ Howard JM, Wynn OB, Lenhart FM et al. Intraluminal duodenum diverticulum: an unusual cause of acute pancreatitis. Am J Surg 1986; 151: 505-508

${ }^{4}$ Afridi SA, Fichtenbaum CJ, Taubin H. Review of duodenal diverticula. Am J Gastroenterol 1991; 86: 935-938

${ }^{5}$ Finnie IA, Ghosh P, Garvey $\mathrm{C}$ et al. Intraluminal duodenal diverticulum causing recurrent pancreatitis: treatment by endoscopic incision. Gut 1994; 35: $557-559$

\section{Corresponding Author}

\section{Q. Quatrini, M.D.}

Dept. Scienze Mediche

Via F. Sforza, 35

20122 Milano

Italy

Fax: $\quad$ +39-02-55012111

E-mail: maurizio_quatrini@yahoo.it 